\title{
PRODUÇÃO DE ETILENOGLICÓIS E DERIVADOS POR REAÇÕES CATALÍTICAS DO ÓXIDO DE ETENO
}

\author{
Leandro Martins e Dilson Cardoso* \\ Departamento de Engenharia Química, Universidade Federal de São Carlos, Rodovia Washington Luís km 235, \\ 13565-905 São Carlos - SP
}

Recebido em 15/1/04; aceito em 15/10/04; publicado na web em 17/2/05

\begin{abstract}
PRODUCTION OF ETHYLENEGLYCOLS AND DERIVATES BY CATALYTIC REACTIONS OF ETHYLENE OXIDE. Products resulting from the ethoxylation of hydroxylated compounds, especially water and ethanol, are of great commercial importance. This work presents several aspects concerning the catalytic reactions of ethylene oxide, a chemical substance used in the production of a wide variety of products. Mechanisms of ethoxylation, distribution of products, formation of undesired by-products and perspectives for new processes using heterogeneous catalysis are also reviewed and discussed.
\end{abstract}

Keywords: ethylene oxide; ethoxylation of $\mathrm{ROH}$; catalysts.

\section{INTRODUÇÃO}

O óxido de eteno (OE) é um intermediário químico utilizado na fabricação de uma grande variedade de produtos, tais como etilenoglicóis, etanolaminas, éteres etílicos e surfactantes não iônicos. A sua demanda mundial anual de 14 milhões de $t$ vem crescendo em torno de $3 \%$, o que faz com que esse composto químico tenha uma importância econômica relevante para um país. O maior produtor mundial do OE é os Estados Unidos, com uma produção anual de 4 milhões de t. A produção anual do Brasil é de $312.000 \mathrm{t}^{1}$, sendo a maior de toda a América Latina e realizada pela empresa Oxiteno ${ }^{2}$. A maior parte desta produção é utilizada em reações com álcoois (metanol, etanol e butanol) e com água para a obtenção, respectivamente, de éteres mistos do etilenoglicol (60.000 t/a) e do monômero e oligômeros do etilenoglicol (310.000 t/a).

Os produtos etilenoglicóis e éteres do etilenoglicol obtidos, respectivamente, a partir da reação do óxido de eteno com água ou álcoois (Equação 1, $\mathrm{R}=\mathrm{H}$ ou $\mathrm{R}=\mathrm{C}_{2} \mathrm{H}_{5}, \mathrm{CH}_{3}, \mathrm{C}_{4} \mathrm{H}_{9}$ ) encontram diversas aplicações, sendo que as mais importantes são:

$i \underset{\mathrm{H}_{2} \mathrm{C}-\mathrm{CH}_{2}}{\mathrm{O}}+\mathrm{ROH} \stackrel{\text { Cat. }}{\longrightarrow} \mathrm{RO}\left(\mathrm{CH}_{2} \mathrm{CH}_{2} \mathrm{O}\right)_{i} \mathrm{H}$

(1) - o mono-etilenoglicol (MEG), utilizado principalmente como anti-congelante, ou como matéria-prima na produção de fibra poliéster ou ainda de poli(tereftalato de etileno) (embalagens PET), correspondendo a um consumo de cerca de 18, 55 e $11 \%$ de sua produção em cada um desses setores, respectivamente ${ }^{3}$.
(2) - os éteres do mono-etilenoglicol (EEMEG) e o do dietilenoglicol (EEDEG), utilizados como solventes de resinas naturais e sintéticas e, também, na formulação de tintas, vernizes e fluidos de freio. A presença dos grupos funcionais éter e uma hidroxila em uma mesma molécula fornece aos éteres de etilenoglicol uma característica ideal de solvência. Os éteres do di- e tri-etilenoglicol, pelo seu elevado ponto de ebulição e baixo ponto de congelamento, são especialmente adequados à formulação de fluidos de freio ${ }^{2}$.

A Tabela 1 mostra a fórmula dos principais derivados do óxido de eteno na reação com água ou com álcoois (mostrado o etanol), e suas siglas usuais.

O óxido de eteno, como a maioria dos epóxidos, é caracterizado pela alta reatividade e de fato é o que se espera de sua estrutura altamente tensionada, devido ao átomo de oxigênio estar ligado a dois átomos de carbono vizinhos. Esse reagente participa facilmente de reações de adição (denominadas de etoxilação) com compostos que possuem um átomo de hidrogênio ativo $\left(\mathrm{ROH}, \mathrm{RNH}_{2}\right.$ ou $\mathrm{R}_{2} \mathrm{NH}$ ), como a água, álcoois e aminas ${ }^{4}$.

Com o objetivo de aumentar a atividade e a seletividade da reação, vários catalisadores vêm sendo usados na etoxilação da água ou de álcoois, especialmente o etanol. Industrialmente, espera-se que esses catalisadores sejam ativos sem a formação excessiva de oligômeros $(i \geq 2)$ e de outros produtos indesejáveis, como as dioxanas, devido ao seu caráter cancerígeno.

A crescente demanda do mercado pelos monômeros (Equação $1, i=1)$ e a necessidade de encontrar processos industriais cada vez mais competitivos faz com que a busca por catalisadores mais

Tabela 1. Fórmula dos principais derivados do óxido de eteno e suas siglas

\begin{tabular}{|c|c|c|c|c|}
\hline \multirow{2}{*}{$\begin{array}{c}\text { Hidroxilado } \\
\mathrm{R} \\
i\end{array}$} & \multicolumn{2}{|c|}{$\begin{array}{c}\text { Água } \\
\text { H }\end{array}$} & \multicolumn{2}{|c|}{$\begin{array}{c}\text { Etanol } \\
\mathrm{C}_{2} \mathrm{H}_{5}\end{array}$} \\
\hline & Fórmula & Sigla & Fórmula & Sigla \\
\hline 1 & $\mathrm{HOCH}_{2} \mathrm{CH}_{2} \mathrm{OH}$ & MEG & $\mathrm{C}_{2} \mathrm{H}_{5} \mathrm{OCH}_{2} \mathrm{CH}_{2} \mathrm{OH}$ & EEMEG \\
\hline 2 & $\mathrm{HO}\left(\mathrm{CH}_{2} \mathrm{CH}_{2}^{2} \mathrm{O}\right)_{2} \mathrm{H}$ & DEG & $\mathrm{C}_{2} \mathrm{H}_{5}^{2} \mathrm{O}\left(\mathrm{CH}_{2} \mathrm{CH}_{2}^{2} \mathrm{O}\right)_{2} \mathrm{H}$ & EEDEG \\
\hline 3 & $\mathrm{HO}\left(\mathrm{CH}_{2} \mathrm{CH}_{2} \mathrm{O}\right)_{3} \mathrm{H}$ & TEG & $\mathrm{C}_{2} \mathrm{H}_{5} \mathrm{O}\left(\mathrm{CH}_{2} \mathrm{CH}_{2} \mathrm{O}\right)_{3} \mathrm{H}$ & EETEG \\
\hline
\end{tabular}


ativos e seletivos tenha um papel estratégico no desenvolvimento de novas tecnologias 5 . Outro fator que tem merecido destaque na busca por novos catalisadores para a etoxilação é o fato de que as configurações padrões atuais de plantas industriais de etilenoglicóis e éteres etílicos de etilenoglicóis consomem grande quantidade de energia. A Figura 1 mostra um esquema exemplificado de uma planta química produtora de glicóis ou etilglicóis ${ }^{6}$. Neste processo, a mistura do óxido de eteno e do reagente $\mathrm{ROH}$ é pré-aquecida ( $200{ }^{\circ} \mathrm{C}$ ) em um sistema de trocadores de calor antes de entrar, na fase líquida, no reator tubular ${ }^{7}$. Após deixar o reator, a mistura de produtos é purificada através da passagem por uma coluna de destilação à baixa pressão. Nestas condições, a co-produção dos oligômeros é inevitável, porque o $\mathrm{OE}$ reage mais rapidamente com o glicol formado (Equação 1, e. g. $\mathrm{R}=\mathrm{HOC}_{2} \mathrm{H}_{4}$ ) que com a água ou o etanol. A formação desses oligômeros pode ser diminuída se um excesso do reagente hidroxilado, $\mathrm{ROH}$, for utilizado.
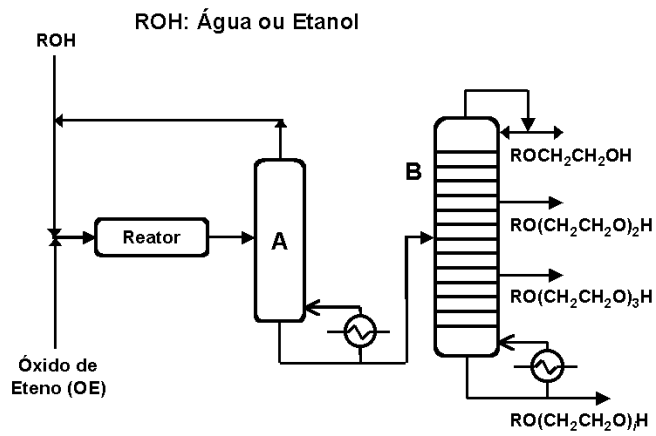

Figura 1. Diagrama de fluxos de uma planta padrão de glicóis ou etilglicóis: (A) Coluna de expansão súbita ("Flash"); (B) Coluna de destilação. Adaptado da ref. 5

Como exemplo, a Figura 2 mostra a composição da mistura resultante da reação do óxido de eteno com água ${ }^{8}$ a $90{ }^{\circ} \mathrm{C}$, em função da razão molar $\mathrm{H}_{2} \mathrm{O} / \mathrm{OE}$ e utilizando-se ácido sulfúrico $(0,5 \%$ $\mathrm{m} / \mathrm{m}$ ) como catalisador. Nessa figura, o índice $\boldsymbol{i}$ representa o grau de oligomerização do produto $\mathrm{HO}\left(\mathrm{CH}_{2} \mathrm{CH}_{2} \mathrm{O}\right)_{i} \mathrm{H}$.

Apesar de os valores apresentados no gráfico da Figura 2 terem sido obtidos com catalisador, os resultados da seletividade se aplicam bem como uma aproximação para a reação sem catalisador ${ }^{6}$. Esses resultados mostram, portanto, que se for desejado produzir o mono-etileno glicol, $\mathrm{HOCH}_{2} \mathrm{CH}_{2} \mathrm{OH}$ (Equação 1, $i=1$ ), a uma

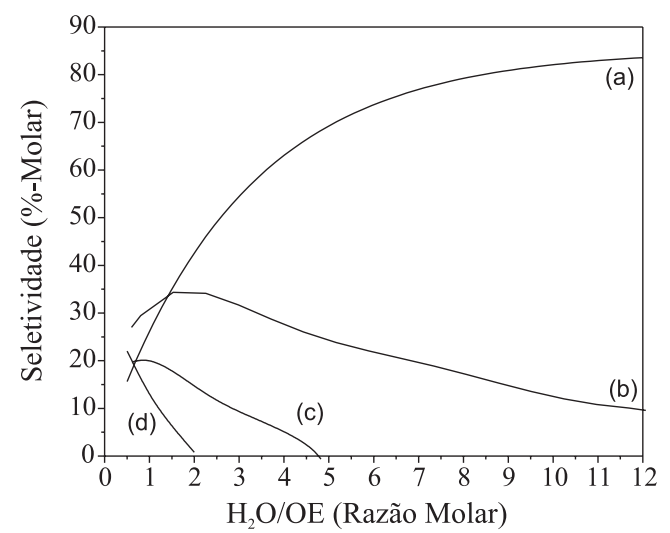

Figura 2. Composição do produto obtido $\left(\mathrm{HO}\left(\mathrm{CH}_{2} \mathrm{CH}_{2} \mathrm{O}\right)_{\mathbf{i}} \mathrm{H}\right)$ na reação do óxido de eteno com água, em função da razão molar $\mathrm{H}_{2} \mathrm{O} / \mathrm{OE}: \mathbf{i}=(a) 1,(b) 2$, (c) 3, (d) 4. Adaptado da ref. 7 seletividade de aproximadamente $85 \%$, segundo a Figura 2 devese utilizar uma razão molar $\mathrm{H}_{2} \mathrm{O} / \mathrm{OE}$ igual ou superior a 12 , motivo pelo qual há grande consumo energético na separação e reciclo do reagente $\mathrm{ROH}$ (Coluna A), pois para cada litro de glicol produzido, há a necessidade de se recircular cerca de $11 \mathrm{~L}$ de água, tanto na fase de vaporização como de condensação.

Muitos estudos vêm sendo realizados para que esses processos atuais de obtenção de etilenoglicóis e éter etílico de etilglicóis sejam melhorados, tanto no sentido de diminuir o excesso do reagente hidroxilado quanto melhorar a seletividade ao monômero. A maioria dos processos industriais utiliza hidróxidos de metais alcalinos como catalisadores. Por outro lado, na literatura têm sido descritos muitos catalisadores, tanto homogêneos quanto heterogêneos, capazes de otimizar a seletividade ao monômero ou de diminuir a temperatura de reação e o excesso do reagente ROH. A busca em evitar a formação de subprodutos, facilitada em determinadas condições reacionais, também tem sido citada na literatura uma vez que, dependendo da composição da mistura que sai do reator, o processo para separação dos produtos desejados fica encarecido.

Nesse contexto, este trabalho apresenta de forma sistemática um levantamento bibliográfico sobre reações de etoxilação catalisadas envolvendo água e álcoois, e as direções da pesquisa nessa área. É apresentado também, um modelo matemático simplificado que permite obter, de forma rápida, informações importantes sobre a seletividade durante a etoxilação.

\section{MECANISMOS DE REAÇÃO - MEIO HOMOGÊNEO}

O emprego da catálise homogênea na etoxilação, apesar das dificuldades de separação do catalisador dos produtos da reação, apresenta uma grande vantagem perante a heterogênea. Como nos atuais processos industriais de etoxilação as reações ocorrem em fase homogênea, as novas descobertas para os catalisadores homogêneos poderão ser aplicadas a curto prazo, sem necessidade de modificações significativas das configurações atuais e de novos investimentos.

A hidroxilação catalítica do óxido de eteno pode ocorrer tanto na presença de bases quanto de ácidos, os quais apresentam algumas diferenças que influenciam no desempenho do reator e, principalmente, no mecanismo de reação. As reações catalisadas por ácidos podem ser realizadas a uma temperatura mais baixa ${ }^{9}, e . g$., a $50-90{ }^{\circ} \mathrm{C}$ ou até mesmo $15^{\circ} \mathrm{C}$, comparado a $80-140^{\circ} \mathrm{C}$ com os catalisadores básicos. Os catalisadores ácidos, apesar de apresentarem uma estreita distribuição de produtos, conduzem à formação de subprodutos e a elevadas quantidades de polietilenoglicóis $(\mathrm{PEG})^{10}$, além de serem muito corrosivos. Esses fatores, portanto, têm limitado o uso de catalisadores ácidos em aplicações industriais. Já os catalisadores básicos, apesar de fornecerem uma distribuição de produtos menos estreita, não conduzem à formação de subprodutos, facilitando o processo de separação.

\section{Etoxilação na presença de ácidos}

Na literatura existem diversas propostas para explicar o mecanismo através do qual o óxido de eteno é adicionado a uma hidroxila ${ }^{4}$ quando se emprega um catalisador que possua sítios ácidos de Brönsted. No entanto, parece ser consenso da maioria dos pesquisadores que essa reação se processa de acordo as etapas descritas a seguir ${ }^{11-14}$.

A reação entre uma molécula de óxido de eteno e um próton ocorre rapidamente (Equação 2) e o produto formado permite que a reação seja reversível, de modo que se pode considerar essa etapa em equilíbrio termodinâmico ${ }^{4}$. A molécula de OE protonada pode, então, ser mais facilmente atacada pela espécie nucleofílica $\mathrm{ROH}$. 
Como será visto a seguir, o mecanismo de reação é diferente dependendo da força do sítio ácido utilizado.

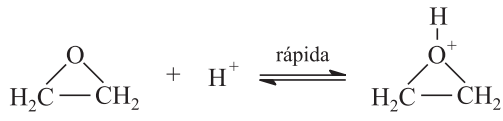

Na presença de ácidos fortes, tais como ácido sulfúrico, o anel do OE protonado é aberto gerando um carbocátion (Equação 3), que é atacado pela espécie $\mathrm{ROH}^{11}$. Neste caso, a velocidade de reação independe da concentração e da estrutura do composto $\mathrm{ROH}$ a ser etoxilado ${ }^{14}$, tendo em vista que a etapa lenta envolve a formação do carbocátion (Equação 3). Nessas circunstâncias, a reação global pode ser classificada como sendo uma substituição nucleofílica do tipo $\mathrm{S}_{\mathrm{N}} 1$ (Equação 4). Se o carbocátion formado não reagir rapidamente com o composto $\mathrm{ROH}$ ele poderá se isomerizar, ocorrendo a formação de acetaldeído e, consequientemente, de outros subprodutos ${ }^{4}$.

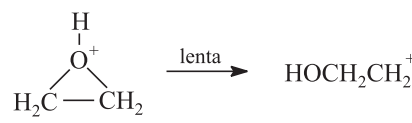

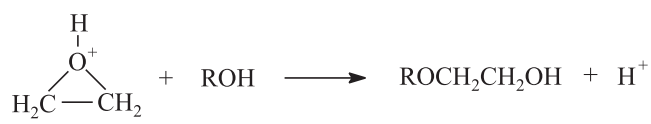

Na presença de ácidos fracos, ao contrário, a reação ocorre através de uma substituição nucleofílica bi-molecular ${ }^{4}\left(\mathrm{~S}_{\mathrm{N}} 2\right)$ e sua cinética depende, portanto, da concentração do óxido de eteno protonado e do composto hidroxilado ROH (Equação 5). Isso possivelmente se deve à formação de um par iônico, entre o $\mathrm{OE}$ protonado e o ânion, o que dá maior estabilidade à espécie ativa, evitando assim a abertura do anel numa primeira etapa. Nesse caso, a etapa lenta envolve tanto o óxido de eteno protonado como o composto $\mathrm{ROH}$, e a reação ocorre através do estado de transição mostrado na Equação 5.

A reação de etoxilação também pode ser catalisada por ácidos de Lewis, geralmente fracos, e é fortemente dependente da presença de solventes polares, os quais influenciam significativamente na velocidade de reação $0^{15}$. O pentacloreto de antimônio, por ex., é um ácido de Lewis que apresenta afinidade por elétrons, devido à presença de orbitais $\boldsymbol{d}$ não preenchidos, e o mecanismo de reação é similar ao que ocorre com ácidos fracos de Brönsted ${ }^{16}$ (Equação 5). Se a etoxilação for realizada na presença do pentacloreto de antimônio, ele interage com o $\mathrm{OE}$ através do átomo de oxigênio, enfraquecendo as ligações $\mathrm{C}-\mathrm{O}$ e facilitando o ataque de um nucleófilo $\mathrm{ROH}$ (Equação 5). Se o solvente formar complexos estáveis com o catalisador a atividade deverá, portanto, diminuir.

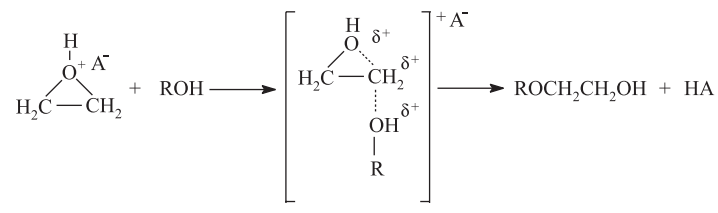

De fato, a estabilidade do complexo catalisador - solvente pode ser quantificada pela entalpia de complexação $\Delta \mathrm{H}_{c}$, também conhecida por "electron donor number". Os valores da entalpia de formação de alguns complexos do pentacloreto de antimônio com solventes são mostrados na Tabela $2{ }^{16}$. Para verificar sua relação com a etoxilação, Klug e colaboradores reagiram o $\mathrm{OE}$ com os álcoois $\beta$-feniletílico $\left(\mathrm{C}_{6} \mathrm{H}_{5}-\mathrm{C}_{2} \mathrm{H}_{4} \mathrm{OH}\right)$ e $\gamma$-fenilpropílico $\left(\mathrm{C}_{6} \mathrm{H}_{5}\right.$ $\left.\mathrm{C}_{3} \mathrm{H}_{6} \mathrm{OH}\right)$ empregando pentacloreto de antimônio como catalisador ${ }^{15}$. Em concordância com os resultados da Tabela 2, a etoxilação apresentou a menor velocidade de reação na presença do solvente mais polar (o bis (2-metoxi-etil) éter). O tolueno, que é o menos polar entre os estudados está em outro extremo, apresentando a maior velocidade de reação e a 1,4-dioxana proporcionou uma atividade intermediária ${ }^{15}$. A atividade catalítica, portanto, diminui com o aumento do número da entalpia de complexação $\mathrm{DH}_{\mathrm{c}}$, na seguinte ordem: $\mathrm{C}_{6} \mathrm{H}_{6}-\mathrm{CH}_{3}>\mathrm{C}_{4} \mathrm{H}_{8} \mathrm{O}_{2}>\left(\mathrm{CH}_{3} \mathrm{OCH}_{2} \mathrm{CH}_{2}\right)_{2} \mathrm{O}$.

Tabela 2. Entalpia de complexação de alguns solventes com o $\mathrm{SbCl}_{5}{ }^{16}$

\begin{tabular}{lcc}
\hline Nome & Composto & $\Delta \mathrm{H}_{\mathrm{c}}(\mathrm{Kcal} / \mathrm{mol})$ \\
\hline Tolueno & $\mathrm{C}_{6} \mathrm{H}_{5}-\mathrm{CH}_{3}$ & $-0,5$ \\
1,4-dioxana & $\mathrm{C}_{4} \mathrm{H}_{8} \mathrm{O}_{2}$ & $-14,8$ \\
bis (2-metoxi-etil) éter & $\left(\mathrm{CH}_{3} \mathrm{OCH}_{2} \mathrm{CH}_{2}\right)_{2} \mathrm{O}$ & $-24,0$ \\
\hline
\end{tabular}

\section{Etoxilação na presença de bases}

O uso de catalisadores básicos, principalmente os hidróxidos inorgânicos hidróxido de sódio e hidróxido de potássio, é praticamente dominante na produção industrial de surfactantes não iônicos ${ }^{17}$, por apresentarem alta atividade e seletividade na obtenção de etoxilados de alto peso molecular. O baixo custo, a facilidade de remoção por neutralização e a não formação de subprodutos são fatores que, também, motivam o uso desses catalisadores na obtenção de mono-derivados a partir da etoxilação da água ou de álcoois. No entanto, neste caso, é necessária a utilização de excesso do reagente hidroxilado $\mathrm{ROH}$ de até 25 vezes do valor estequiométrico, de maneira a garantir a produção preferencial dos mono-etoxilados, que apresentam maior valor comercial.

Ao contrário da catálise ácida, na catálise básica a ênfase maior é dada ao caráter nucleófilo da base conjugada do reagente $\mathrm{ROH}$, cuja concentração é aumentada pela adição de um hidróxido $\mathrm{MOH}^{12}$, em que $\mathrm{M}$ geralmente representa um metal alcalino. A abertura do anel do epóxido ocorre como consequiência do ataque nucleofílico RO' a um dos dois carbonos do OE, como mostrado na Equação 6. $\mathrm{O}$ reagente $\mathrm{RO}^{-} \mathrm{M}^{+}$pode ser introduzido no meio reacional ou formado in situ pela reação entre o catalisador com o substrato orgânico, ROH (Equação 7).

$\underset{\mathrm{H}_{2} \mathrm{C}-\mathrm{CH}_{2}}{\mathrm{O}}+\mathrm{RO}^{-} \longrightarrow\left[\begin{array}{c}\mathrm{C} \\ \mathrm{H}_{2} \mathrm{C}-\mathrm{CH}_{2} \\ \mathrm{RO}\end{array}\right]^{-} \longrightarrow \mathrm{ROCH}_{2} \mathrm{CH}_{2} \mathrm{O}^{-}$

$\mathrm{ROH}+\mathrm{MOH} \rightleftharpoons \mathrm{RO}^{-} \mathrm{M}^{+}+\mathrm{H}_{2} \mathrm{O}$

A condensação catalisada do OE com reagentes hidroxilados ocorre de forma similar a uma reação de polimerização ${ }^{18}$, com a formação, a cada etapa, de compostos de cadeias cada vez maiores (Equações 8-10). A diferença, no entanto, é que a polimerização clássica, ao contrário da catalítica, é induzida por um iniciador. A primeira etapa da etoxilação é a reação de inicialização, seguida da propagação e da finalização, sendo que nesta última é recuperada a espécie $\mathrm{RO}^{-} \mathrm{M}^{+}$, que inicia a reação.

\section{Inicialização}

$\mathrm{RO}^{-} \mathrm{M}^{+}+\mathrm{C}_{2} \mathrm{H}_{4} \mathrm{O} \longrightarrow \mathrm{ROC}_{2} \mathrm{H}_{4} \mathrm{O}^{-} \mathrm{M}^{+}$ 
Propagação

$$
\mathrm{RO}\left(\mathrm{C}_{2} \mathrm{H}_{4} \mathrm{O}\right)_{i}^{-} \mathrm{M}^{+}+\mathrm{C}_{2} \mathrm{H}_{4} \mathrm{O} \longrightarrow \mathrm{RO}\left(\mathrm{C}_{2} \mathrm{H}_{4} \mathrm{O}\right)_{i+1}^{-} \mathrm{M}^{+}
$$

Finalização

$$
\mathrm{RO}\left(\mathrm{C}_{2} \mathrm{H}_{4} \mathrm{O}\right)_{n}^{-} \mathrm{M}^{+}+\mathrm{ROH} \stackrel{K_{e}^{\mathrm{n}}}{\rightleftharpoons} \mathrm{RO}\left(\mathrm{C}_{2} \mathrm{H}_{4} \mathrm{O}\right)_{n} \mathrm{H}+\mathrm{RO}^{-} \mathrm{M}^{+}
$$

A velocidade de reação e a seletividade ao mono-etoxilado podem ser maiores ou menores dependendo da influência dos pares iônicos (Equação 10) nas constantes de equilíbrio $K_{e}^{n}$, na etapa de finalização. Tanto o par iônico $\mathrm{RO}^{-} \mathrm{M}^{+}$quanto o íon $\mathrm{RO}^{-}$apresentam atividade, mas este último apresenta constante cinética dez vezes maior, a $30{ }^{\circ} \mathrm{C}$ e empregando hidróxido de sódio como catalisador ${ }^{19}$. Quando o raio do cátion $\mathrm{M}^{+}$é aumentado de 0,6 a $1,33 \AA$ (do $\mathrm{LiOH}$ ao $\mathrm{KOH}$ ) é possível notar um aumento na velocidade da reação e na seletividade ao mono-etoxilado ${ }^{20,21}$. O hidróxido de césio, por sua vez, apresenta melhores resultados, mas seu alto custo inviabiliza a aplicação industrial.

\section{O papel da acidez do substrato}

A diferença de acidez entre o substrato $\mathrm{ROH}$ e seus derivados etoxilados $\mathrm{RO}\left(\mathrm{C}_{2} \mathrm{H}_{4} \mathrm{O}\right)_{i} \mathrm{H}$ influenciam, também, na distribuição de produtos e, portanto, na seletividade da reação. A composição do meio reacional dependerá da velocidade de formação dos etoxilados $\mathrm{RO}\left(\mathrm{C}_{2} \mathrm{H}_{4} \mathrm{O}\right)_{i} \mathrm{H}$ nas etapas de propagação. Sendo assim, quanto mais ácido for o composto $\mathrm{ROH}$, maior será a concentração da espécie $\mathrm{RO}^{-}$em solução e, portanto, mais rápida será a velocidade da primeira etoxilação. Por exemplo, na etoxilação do fenol (também conhecido como ácido fênico), a formação de hidroxilados com mais de duas moléculas de OE (i. e. $i \geq 2$ ) passa a ser significativa somente após a conversão de todo o reagente inicial, ou seja, razão molar OE/fenol > 1,0 $0^{11,21}$. A maior acidez do fenol $\left(\mathbf{C}_{6} \mathbf{H}_{5} \mathrm{OH}\right)$, em comparação com seus derivados etoxilados, $\mathbf{C}_{6} \mathbf{H}_{5} \mathrm{O}\left(\mathrm{CH}_{2} \mathrm{CH}_{2} \mathrm{O}\right)_{i} \mathrm{H}$, deve-se à maior proximidade do grupo $\mathrm{OH}$ terminal ao anel aromático. Na Tabela 3 são mostrados valores de $p K a$ (ou seja, - $l o g$ $K a$ ), de alguns compostos hidroxilados. Quanto menor esse valor mais ácido será o composto. Como é possível observar, o etanol é o menos ácido e o fenol o mais ácido dentre os listados.

Tabela 3. Valores de $p K a$ para diferentes compostos hidroxilados ${ }^{20}$

\begin{tabular}{lc}
\hline Composto & $p K a$ \\
\hline Fenol & 9,90 \\
MEG & 14,22 \\
EEMEG & $14,50^{*}$ \\
Metanol & 15,00 \\
Água & 15,70 \\
Etanol & 16,00 \\
\hline
\end{tabular}

* Valor aproximado

Através da Equação 11 é possível descrever como ocorre a formação dos etoxilados superiores, em função do caráter ácido do composto hidroxilado empregado na etoxilação. Quanto mais ácido for o hidroxilado $\mathrm{ROH}$ em comparação ao seu derivado $\mathrm{RO}\left(\mathrm{CH}_{2} \mathrm{CH}_{2} \mathrm{O}\right)_{i} \mathrm{H}$, como ocorre na etoxilação do fenol, $\mathrm{k}_{1}{ }^{\prime}>\mathrm{k}_{2}$. No entanto, se o composto etoxilado formado, $\mathrm{RO}\left(\mathrm{CH}_{2} \mathrm{CH}_{2} \mathrm{O}\right)_{i} \mathrm{H}$, for mais ácido que o hidroxilado anterior, ou seja $\mathrm{RO}\left(\mathrm{CH}_{2} \mathrm{CH}_{2} \mathrm{O}\right)_{i-1} \mathrm{H}$, a formação de homólogos de massa molecular mais elevada é favorecida, $\mathrm{k}_{1}{ }^{\prime}<\mathrm{k}_{2}$. A Tabela 3 mostra que a formação de DEG e de EEDEG é favorecida, na etoxilação da água ou do etanol, respectivamente, devido ao fato dos compostos MEG e EEMEG apresen- tarem maior acidez que os hidroxilados de partida.

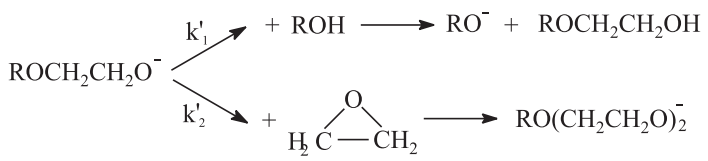

\section{MECANISMO DE REAÇÃO - MEIO HETEROGÊNEO}

Atualmente, o emprego da etoxilação de hidroxilados de baixa massa molecular, por meio da catálise heterogênea, vem crescendo através do uso de catalisadores mais eficientes, especialmente no sentido de obter distribuição de produtos mais estreita. Pesquisas nessa área vêm se intensificando devido ao objetivo de encontrar um catalisador com atividade e seletividade elevadas, e que possa, principalmente, ser separado com facilidade da mistura reacional, possibilitando a operação contínua do reator. Os resultados obtidos são considerados como estratégicos por muitas empresas, o que tem refletido no grande número de descobertas recentemente patenteadas. Por este motivo, na maioria das vezes, as informações obtidas com essas pesquisas são protegidas pelas empresas e, quando publicadas, não é dado muito destaque à informação científica.

Apesar da pouca informação científica que tem sido obtida sobre os processos que usam esses catalisadores, foi sugerido um possível mecanismo envolvendo um par bifuncional ácido-básico, quando se empregam óxidos metálicos que possuam um mínimo de basicidade, como por exemplo, óxidos mistos de Al-Mg-V e zeólitas, que são alumino-silicatos cristalinos ${ }^{14,23}$. O sítio básico de Lewis $\left(\mathrm{O}^{2-}\right)$, presente na superfície do óxido, seria o responsável por ativar o hidrogênio da hidroxila do substrato $\mathrm{ROH}$ a ser etoxilado. Em paralelo, o OE seria ativado em um sítio ácido de Lewis $\left(\mathrm{M}^{2+}\right)$, necessariamente vizinho ao anterior, como mostra o Esquema 1.

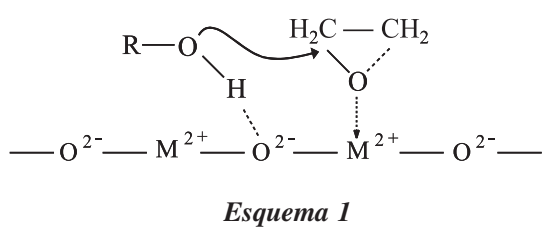

Alguns resultados importantes demonstrando um mecanismo sincronizado semelhante, na presença de óxidos mistos de $\mathrm{Al}-\mathrm{Mg}$, foram obtidos por Hama e colaboradores ${ }^{24}$. Empregando-se a sistemática de Climent e colaboradores, mudando o cátion $\mathrm{M}^{+} \mathrm{e}$ as condições de ativação do óxido metálico, seria possível encontrar um material que apresentasse um desempenho apropriado para a etoxilação dos hidroxilados $\mathrm{ROH}{ }^{25}$.

As hidrotalcitas também têm sido investigadas como grupos de materiais cataliticamente ativos, na obtenção seletiva de monoetoxilados ${ }^{26}$. Hidrotalcitas são argilas com estrutura lamelar que apresentam a fórmula geral $\left[\mathrm{M}_{1-x}{ }^{2+} \mathrm{M}_{x}{ }^{3+}(\mathrm{OH})_{2}\right]\left[\mathrm{A}_{x / m}{ }^{\mathrm{m}-} \cdot \mathrm{nH}_{2} \mathrm{O}\right]$, em que $x$ pode variar de 0,17 a 0,33 , dependendo da combinação entre os cátions bivalente $\mathrm{M}^{2+}$ e trivalente $\mathrm{M}^{3+}$. Particularmente, hidrotalcitas com a composição $\left[\mathrm{Mg}_{1-x} \mathrm{Al}_{x}(\mathrm{OH})_{2}\right]\left[\left(\mathrm{CO}_{3}\right)_{x / 2} \cdot \mathrm{nH}_{2} \mathrm{O}\right]$ têm sido largamente utilizadas em pesquisas envolvendo etoxilação, por causa da acidez gerada por cátions de $\mathrm{Al}^{3+}$ isolados. Na Figura 3 é mostrado um provável mecanismo de reação ocorrendo na superfície de hidrotalcitas ${ }^{27}$. o qual seria o responsável pela estreita distribuição de produtos que tem sido obtida. De acordo com esse mecanismo, à medida que se aumenta o número de moléculas de $\mathrm{OE}$ adicionadas ao reagente $\mathrm{ROH}$, aumenta o número de sítios ácidos $\mathrm{Al}^{3+}$ ocupados pela adsorção dos 
átomos de oxigênio presentes no $\mathrm{RO}\left(\mathrm{CH}_{2} \mathrm{CH}_{2} \mathrm{O}\right)_{i}^{-}$. Como conseqüência, há menos sítios $\mathrm{Al}^{3+}$ disponíveis próximos do ponto de crescimento do alcoolato $\mathrm{RO}\left(\mathrm{CH}_{2} \mathrm{CH}_{2} \mathrm{O}\right)_{i}$, o que leva a uma diminuição do número de moléculas de $\mathrm{OE}$ adsorvidas. Inversamente, a etoxilação de hidroxilados de cadeia menor é favorecida observando-se, portanto, maior seletividade aos etoxilados de menor massa molecular. O mecanismo proposto justificaria, também, o fato da velocidade de reação diminuir ao longo do tempo pela ocupação dos sítios ácidos de Lewis ${ }^{27}$.

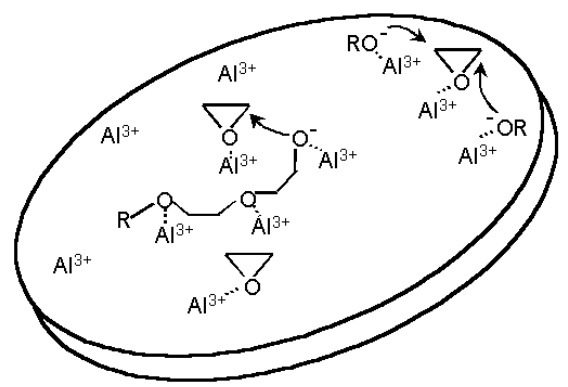

Figura 3. Esquema proposto para etoxilação na superfície de uma hidrotalcita (R: grupo dodecil). Reproduzido da ref. 27, com permissão da Elsevier Science

Materiais baseados em argilas naturais, e. g. montmorilonita, com estruturas similares às das hidrotalcitas, e trocados com cátions de metais de terras-raras também têm sido estudados e patentea$\operatorname{dos}^{28,29}$. No entanto, esses materiais, por serem naturais, apresentam uma grande desvantagem para aplicação industrial por não apresentarem uma composição química constante.

Concomitante com os efeitos da composição do catalisador na determinação do mecanismo de reação e, conseqüentemente, na distribuição de produtos, materiais microporosos de diferentes estruturas e com seletividade de forma têm sido propostos para essa reação. A catálise com seletividade de forma é uma característica de peneiras moleculares microporosas (e. g. zeólitas) bastante utilizada em processos industriais, desde a sua descoberta como catalisadore $^{30}$. Esta seletividade, que depende principalmente da estrutura da peneira, pode ser dividida em seletividade de forma a reagentes, produtos e a estados de transição ${ }^{31-33}$. As duas primeiras estão relacionadas com a maior ou menor difusão dos reagentes através dos canais microporosos da peneira e a última, a efeitos estéricos, devido ao espaço limitado para que a reação ocorra (Figura 4). Estas três propriedades conduzem à formação ou obtenção preferencial das moléculas de menor diâmetro cinético.

No caso das reações de etoxilação as zeólitas, com geometria de poros e estruturas diversas, apresentaram um pequeno aumento de seletividade aos mono-etoxilados, indicando um possível efeito

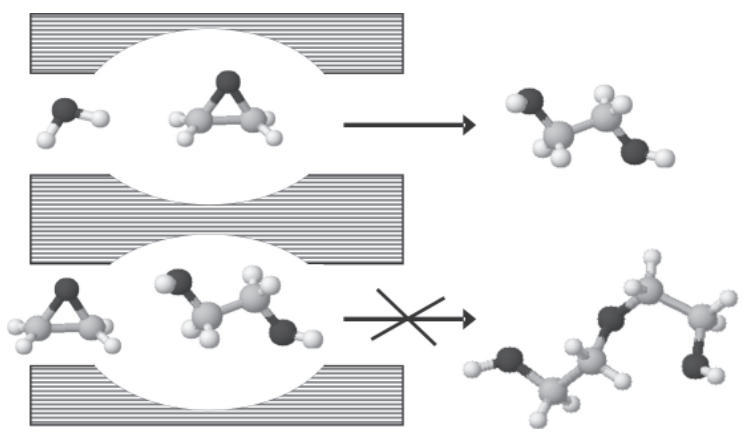

Figura 4. Provável seletividade de forma por restrição a estado de transição, na etoxilação da geometria dos poros desses materiais na obtenção de compostos de menor diâmetro cinético ${ }^{34}$. Deve-se alertar, no entanto, para o fato de que se a superfície externa da zeólita possuir sítios catalíticos, que não estão sujeitos às restrições estéricas e difusionais como aqueles presentes no interior dos canais, a reação de interesse e outras indesejáveis podem ocorrer concomitante sobre esta superfície.

Geralmente na catálise se experimenta um número grande catalisadores, com composição, estruturas e condições reacionais diversificadas, de forma a encontrar a combinação desejada para a obtenção de um determinado produto. Uma forma de comparação do desempenho dos catalisadores é através uso de modelos cinéticos simplificados. Como discutido a seguir, existem alguns modelos na literatura que descrevem satisfatoriamente o comportamento de uma reação série-paralela, particularmente, a reação de etoxilação.

\section{A MODELAGEM CINÉTICA SIMPLIFICADA DA ETOXILAÇÃO}

Os dados experimentais de etoxilação, que fornecem a composição do meio reacional ao longo do tempo, podem ser caracterizados por parâmetros estimados através do uso de vários modelos teóricos de distribuição de produtos. Esses modelos, baseados no princípio de cinética de reação, são utilizados na determinação dos coeficientes de distribuição de produtos (CDP), os quais permitem prever o consumo do hidroxilado $\mathrm{ROH}$ e a seletividade aos homólogos ${ }^{35,36}$.

Existem três funções matemáticas (Tabela 4) que podem ser utilizadas na determinação dos $\mathrm{CDP}^{34}$, baseadas em um modelo simples de reações sucessivas entre um reagente hidroxilado $\left(\mathrm{RO}\left(\mathrm{C}_{2} \mathrm{H}_{4} \mathrm{O}\right)_{\mathrm{i}} \mathrm{H}\right)$ e o óxido de eteno, apresentadas nas Equações de 12 a 14.

$$
\begin{aligned}
& \mathrm{ROH}+\mathrm{C}_{2} \mathrm{H}_{4} \mathrm{O} \stackrel{\mathrm{k}_{0}}{\longrightarrow} \mathrm{ROC}_{2} \mathrm{H}_{4} \mathrm{OH} \\
& \mathrm{ROC}_{2} \mathrm{H}_{4} \mathrm{OH}+\mathrm{C}_{2} \mathrm{H}_{4} \mathrm{O} \stackrel{\mathrm{k}_{1}}{\longrightarrow} \mathrm{RO}\left(\mathrm{C}_{2} \mathrm{H}_{4} \mathrm{O}\right)_{2} \mathrm{H} \\
& \mathrm{RO}\left(\mathrm{C}_{2} \mathrm{H}_{4} \mathrm{O}\right)_{\mathrm{i}} \mathrm{H}+\mathrm{C}_{2} \mathrm{H}_{4} \mathrm{O} \stackrel{\mathrm{k}_{\mathrm{i}}}{\longrightarrow} \mathrm{RO}\left(\mathrm{C}_{2} \mathrm{H}_{4} \mathrm{O}\right)_{\mathrm{i}+1} \mathrm{H}
\end{aligned}
$$

Nessas equações, $\mathrm{k}_{0}, \mathrm{k}_{1}, \ldots, \mathrm{k}_{\mathrm{i}}$ são constantes de velocidade das reações de etoxilação. Na reação com os hidroxilados, se as constantes de velocidade de reação aumentarem nas sucessivas etapas $\left(\mathrm{k}_{\mathrm{i}}>\right.$ $\ldots>\mathrm{k}_{1}>\mathrm{k}_{0}$ ), uma quantidade maior de oligômeros será formada já no início da etoxilação e, no final, haverá uma grande quantidade de reagente $\mathrm{ROH}$ não convertido, mesmo se for utilizada uma razão estequiométrica $1: 1^{37}$. Portanto, para a obtenção de etoxilados de baixa massa molecular, o ideal seria que $\mathrm{k}_{0}$ tivesse o maior valor possível e que $\mathrm{k}_{1}$ fosse menor que $\mathrm{k}_{0}$, mas igual ou maior que $\mathrm{k}_{2} \mathrm{e}$ assim por diante, ou seja: $\mathrm{k}_{0}>\mathrm{k}_{1} \geq \mathrm{k}_{2} \geq \ldots . \mathrm{k}_{\mathrm{i}}$. Esta situação, no entanto, está pouco distante da realidade, pois na etoxilação na presença de bases, o que se observa é que $\mathrm{k}_{0}<\mathrm{k}_{1}<\mathrm{k}_{2}<\ldots<\mathrm{k}_{\mathrm{i}}^{38,39}$.

Os coeficientes de distribuição de produtos (CDP) são definidos como a razão das constantes de velocidade: $C_{1}=\mathrm{k}_{1} / \mathrm{k}_{0}, C_{2}=\mathrm{k}_{2} / \mathrm{k}_{0}$,

Tabela 4. Coeficientes de distribuição de produtos e constantes cinéticas

\begin{tabular}{lllll}
\hline No $^{\circ}$ & Equação & CDP & $\begin{array}{l}\text { Constantes } \\
\text { Cinéticas }\end{array}$ & Ref. \\
\hline $\mathbf{1}$ & Flory & $C=1,0$ & $\mathrm{k}_{0}=\mathrm{k}_{1}=\ldots=\mathrm{k}_{\mathrm{i}}$ & 46 \\
$\mathbf{2}$ & Weibull-Nycander & $C=\mathrm{k} / \mathrm{k}_{0}$ & $\mathrm{k}_{0} \neq \mathrm{k}_{1}=\ldots=\mathrm{k}_{\mathrm{i}}=\mathrm{k}$ & 35 \\
$\mathbf{3}$ & Natta & $C_{i}=\mathrm{k}_{\mathrm{i}} / \mathrm{k}_{0}$ & $\mathrm{k}_{0} \neq \mathrm{k}_{1} \neq \ldots \neq \mathrm{k}_{\mathrm{i}}$ & 49 \\
\hline
\end{tabular}


..., $C_{i}=\mathrm{k}_{\mathrm{i}} / \mathrm{k}_{0}$. As frações molares dos homólogos $\mathrm{RO}\left(\mathrm{C}_{2} \mathrm{H}_{4} \mathrm{O}\right)_{i} \mathrm{H}$ são descritas como $\boldsymbol{x}_{\boldsymbol{i}}$ (ex.: $x_{0}=$ água e $\left.x_{1}=\mathrm{MEG}\right)$ e o consumo de $\mathrm{OE}$ como $n$, razão molar entre $\mathrm{OE}$ consumido e o reagente hidroxilado inicial $\left(\mathrm{OE} / \mathrm{ROH}_{0}\right)$. O número de moles de $\mathrm{OE}$ consumido pode ser obtido através de balanço de material, considerando o número de moles de etoxilados produzidos.

Um dos problemas no estudo da cinética destas reações através do uso de modelos cinéticos, baseados no mecanismo de reação, está na dificuldade de se obter corretamente as expressões que descrevem a solubilidade do $\mathrm{OE}$ e a densidade da fase líquida à medida que o grau de etoxilação da mistura avança $a^{40-43}$. É por esse motivo que os CDP são mais explorados na literatura. Apesar do grande número de informações obtidas com aqueles modelos, tal como conversão de OE e perfil de temperatura ao longo do reator, a maior facilidade matemática na determinação dos CDP faz com que o seu uso seja mais freqüente ${ }^{44}$. Como já discutido, os etilenoglicóis e os éteres etilenoglicólicos são produtos químicos que apresentam elevada importância em diversas aplicações comerciais ${ }^{45}$. Portanto, é de interesse da indústria conhecer, de forma rápida e simples, a relação entre a distribuição dos produtos etoxilados com as variáveis de processo, tal como temperatura do reator e concentração de catalisador. Quanto menor os valores dos coeficientes $C_{i}$ $\left(\mathrm{k}_{\mathrm{i}} / \mathrm{k}_{0}\right)$, mais seletivo será o catalisador aos produtos de maior interesse comercial, ou seja, o mono-etilenoglicol ou os éteres do monoetilenoglicol.

Se as reações entre o $\mathrm{OE}$ e os hidroxilados $\mathrm{RO}\left(\mathrm{C}_{2} \mathrm{H}_{4} \mathrm{O}\right)_{i} \mathrm{H}$ forem cineticamente semelhantes, com constantes cinéticas muito próximas, os coeficientes de distribuição de produtos serão iguais a 1 e, nesta condição, Flory demonstrou que a distribuição segue a função de Poisson (Tabela 4, Equação 1) ${ }^{46}$. Este modelo matemático é muito simples, e se aplica somente de forma aproximada à formação de alguns mono-éteres, como o $\mathrm{MEG}^{47}$.

Weibull e Nycander, e mais tarde Gold, assumiram a hipótese de que a velocidade da primeira reação (Equação 12), na qual participa um hidroxilado $\mathrm{ROH}$ que não possui um grupo etil-éter$\mathrm{C}_{2} \mathrm{H}_{4} \mathrm{O}$ - (por exemplo, $\mathrm{H}_{2} \mathrm{O}$ ou $\mathrm{C}_{2} \mathrm{H}_{5} \mathrm{OH}$ ), difere cineticamente das reações seguintes ${ }^{35,48}$. Nestas, o grupo etil-éter está sempre presente na forma de $\left(\mathrm{RO}\left(\mathrm{C}_{2} \mathrm{H}_{4} \mathrm{O}\right)_{i} \mathrm{H}\right)$, conferindo à hidroxila terminal a mesma reatividade. Nestas condições, o $\mathrm{CDP}\left(\mathrm{k}_{\mathrm{i}} / \mathrm{k}_{0}\right)$ é um número constante, definido como $C$, e diferente de 1 . Utilizando o modelo de Weibull-Nycander para baixos valores de $v\left(\mathrm{OE} / \mathrm{ROH}_{0}\right)$, os valores constantes de $C$, empregando diversos catalisadores, foram confirmados experimentalmente ${ }^{35}$.

O modelo geral e o mais complicado de todos, no qual todas as reações são cineticamente diferentes, foi proposto por Natta ${ }^{49}$. Este modelo, aplicado para altos valores de $n$, apresenta um CDP $C_{i}$ para cada composto $\mathrm{RO}\left(\mathrm{C}_{2} \mathrm{H}_{4} \mathrm{O}\right)_{i} \mathrm{H}$ presente no meio reacional.

O modelo proposto por Weibull e Nycander é o mais utilizado na literatura, por ser mais simples que o de Natta e por aproximarse bastante das reações envolvendo o $\mathrm{OE}$ e $\mathrm{ROH}^{12,35,49}$. As Equações 15 e 16 mostram as funções matemáticas decorrentes do modelo de Weibull-Nycander, utilizadas na determinação do coeficiente $C$. Uma vez determinado este valor, é possível prever a distribuição de produtos etoxilados e, portanto, a seletividade da reação, para diferentes valores de $\mathrm{v}\left(\mathrm{OE} / \mathrm{ROH}_{0}\right)$.

$x_{i}=\frac{C^{i-1}}{(C-1)^{i}} \cdot\left\{x_{0}-\left(x_{0}\right)^{C} \cdot \sum_{j=0}^{i-1} \frac{1}{j !} \cdot\left[(1-C) \cdot \ln \left(x_{0}\right)\right]^{j}\right\}$

$C=\frac{x_{0}+v-1}{x_{0}-\ln \left(x_{0}\right)-1}$

\section{A MODELAGEM CINÉTICA NA CATÁLISE HOMOGÊNEA}

O uso da modelagem simplificada de Weibull-Nycander na etoxilação catalítica homogênea, além de fornecer informações sobre o desempenho do catalisador, é uma ferramenta que auxilia também na compreensão da influência das variáveis de processo, $i$. $e$. temperatura, pressão e concentração de catalisador, na composição da mistura que sai do reator. Por esses motivos, o modelo de Weibull-Nycander tem sido utilizado com freqüência no estudo e na otimização da etoxilação em meio homogêneo.

Apesar do uso dominante das bases de Brönsted (hidróxidos inorgânicos, hidróxidos de sódio e de potássio) na indústria, as bases de Lewis e os ácidos em geral também podem ser empregados como catalisadores em meio homogêneo. Na Figura 5 são mostrados, como exemplo, resultados da fração molar dos componentes hidroxilados $\mathrm{RO}\left(\mathrm{CH}_{2} \mathrm{CH}_{2} \mathrm{O}\right)_{i} \mathrm{H}$, em função da razão molar $\mathrm{OE} / \mathrm{ROH}_{0}$, na etoxilação da água a $90{ }^{\circ} \mathrm{C}$, empregando $\mathrm{H}_{2} \mathrm{SO}_{4} 0,5 \%$ $(\mathrm{m} / \mathrm{m})$ como catalisador. Os pontos mostrados na Figura correspondem aos dados experimentais ${ }^{8}$. As funções que representam as curvas foram calculadas a partir das Equações 15 e 16 encontrando-se que $C=1,66$, ou seja, que a reação entre o $\mathrm{OE}$ e a água é 1,66 vezes mais lenta que as demais reações ${ }^{35}$. Através da Figura 5 é possível notar também que, após o consumo de OE correspondente a uma razão molar $v=1 \mathrm{e}$, portanto estequiométrica, $44 \%$ dos moles presentes na mistura ainda são referentes à água. Por conseguinte, isso indica que o $\mathrm{OE}$ reage preferencialmente com os derivados etoxilados formados durante a reação. Com os resultados dos CDP (Tabela 4) é possível estimar a composição dos etoxilados no meio reacional, em função de diferentes razões molares OE/ $\mathrm{ROH}_{0}$, alimentadas ao reator.

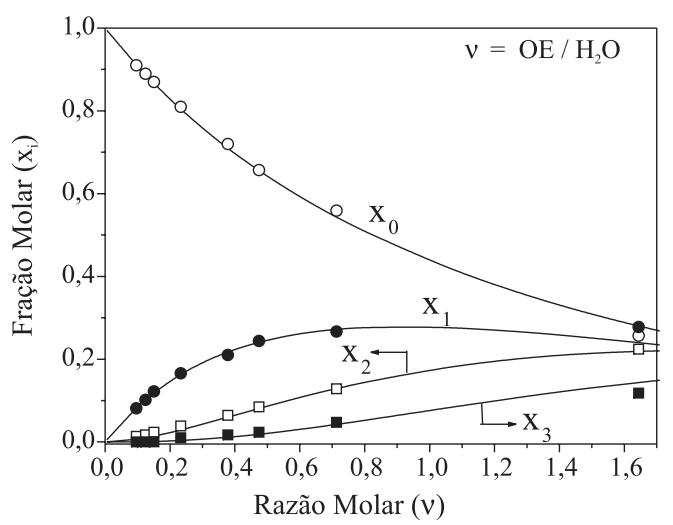

Figura 5. Fração molar, $x_{\mathrm{i}}$ dos compostos presentes na reação do óxido de eteno com água, na presença de ácido sulfúrico $(\mathrm{i}=$ moléculas de $\mathrm{OE}$ adicionadas, $\mathrm{C}=1,66)$. Reproduzida da ref. 35, com permissão da The Swedish Chemical Society

Na Tabela 5 são apresentados os resultados do ajuste do coeficiente $C$ na etoxilação de dois álcoois empregando diferentes catalisadores ${ }^{50}$. Ao se utilizar 2 moles de $\mathrm{OE}$ na etoxilação do álcool n- $\mathrm{C}_{12} \mathrm{H}_{25} \mathrm{OH}$, o catalisador hidróxido de lítio apresentou-se menos seletivo ao mono-etoxilado com um valor de $C\left(\mathrm{k} / \mathrm{k}_{0}\right)$ igual a 4,4 . O catalisador hidróxido de potássio, ao contrário, foi o mais seletivo, indicando que o aumento do raio do cátion diminui a estabilidade dos pares iônicos $\mathrm{RO}^{-} \mathrm{M}^{+}$e $\mathrm{RO}\left(\mathrm{CH}_{2} \mathrm{CH}_{2} \mathrm{O}\right)_{i} \mathrm{M}^{+}$, favorecendo a obtenção dos mono-etoxilados ${ }^{36}$. Espera-se, portanto, que hidróxidos $\mathrm{MOH}$ com cátion de maior raio iônico, e. $g$. hidróxido orgânico $\left[\mathrm{N}\left(\mathrm{CH}_{2} \mathrm{CH}_{2} \mathrm{CH}_{3}\right)_{4}\right]^{-} \mathrm{OH}^{+}$, apresentem melhores resultados. O maior raio do cátion implicaria, também, numa menor interação com os 
nucleófilos $\mathrm{RO}\left(\mathrm{CH}_{2} \mathrm{CH}_{2} \mathrm{O}\right)_{i}^{-}$, resultando no aumento da concentração desta ultima espécie e, portanto, maior velocidade de etoxilação. A Tabela 5 mostra ainda que os catalisadores pentacloreto de antimônio e trifluoreto de boro, por sua vez, são mais seletivos aos mono-etoxilados, mas, como será visto adiante, favorecem a formação de subprodutos não hidroxilados, como decorrência de mudança no mecanismo de reação.

Tabela 5. Coeficientes de distribuição de produtos para diferentes catalisadores $^{50}$

\begin{tabular}{ccccc}
\hline Álcool & $v$ & Catalisador & $\%(\mathrm{~m} / \mathrm{m})^{*}$ & $C$ \\
\hline $\mathrm{n}-\mathrm{C}_{12} \mathrm{H}_{25} \mathrm{OH}$ & 2,0 & $\mathrm{LiOH}$ & 0,5 & 4,4 \\
$\ldots$ & 2,0 & $\mathrm{NaOH}$ & 0,3 & 3,2 \\
$\ldots$ & 2,0 & $\mathrm{KOH}$ & 0,5 & 2,7 \\
$\ldots$ & 4,0 & $\mathrm{SbCl}_{5}$ & 0,5 & 0,8 \\
$\mathrm{n}_{-} \mathrm{C}_{6} \mathrm{H}_{13} \mathrm{OH}$ & 3,0 & $\mathrm{SbCl}_{5}$ & 0,4 & 0,6 \\
$\ldots$ & 3,0 & $\mathrm{BF}_{3}$ & 0,5 & 1,7 \\
\hline
\end{tabular}

* g de catalisador/100 g de $\mathrm{ROH}_{0}$

Recentemente alguns pesquisadores observaram que quando há a formação de hidroxilados de alto grau de etoxilação $(i \geq 3)$, na presença de hidróxidos alcalinos, os coeficientes $C_{i}$ aumentam com a razão molar $\mathrm{OE} / \mathrm{ROH}_{0}$. Este comportamento, descrito como efeito Weibull-Törnquist, é resultado da complexação dos cátions $\mathbf{M}^{+}$ pelos átomos de oxigênio presentes na cadeia do éter, como mostrado no Esquema $2^{51}$. A complexação enfraquece a interação aniônica no par $\mathrm{RO}\left(\mathrm{CH}_{2} \mathrm{CH}_{2} \mathrm{O}\right)_{i}{ }^{-} \mathrm{M}^{+}$, tornando o respectivo alcoolato mais reativo com o OE. Na etoxilação de hidroxilados de cadeia curta, esse efeito tem se mostrado desprezível. No entanto, deve-se alertar que a determinação do coeficiente $C$ deve ser realizada com pontos obtidos com diferentes razões $\mathrm{OE} / \mathrm{ROH}_{0}$, como na Figura 5, para que se verifique a ausência da complexação do cátion pelos átomos do oxigênio do éter.

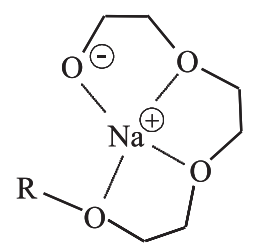

Esquema 2

Como mencionado, os CDP são influenciados pelas variáveis de processo: (1) concentração do catalisador e (2) temperatura de reação ${ }^{52}$. Esta última aumenta ao longo do reator tubular (Figura 1) como consequiência da alta energia liberada durante a reação. Por exemplo, a reação entre a água e o $\mathrm{OE}$ libera $-79,4 \mathrm{KJ} / \mathrm{mol}^{6}$. Como resultado do aumento da temperatura ao longo do reator, o coeficiente $C$ de Weibull-Nycander pode variar de acordo com a Equação 17, que provém de uma derivação dos modelos de Arrhenius e de Hofmann ${ }^{52}$.

$C=C^{0} \cdot \exp \left(\frac{B}{R \cdot T}\right)$

Na Figura 6 é mostrado o resultado proveniente de uma simulação da Equação 17 , para $B=0,5$ e $-0,5 \mathrm{Kcal} / \mathrm{mol}$ e assumindo $C^{0}$ igual à unidade. Se um sistema em particular apresentar o valor de $B$ positivo, ao variar a temperatura de reação de 20 a $100{ }^{\circ} \mathrm{C}$, o valor de $C$ cairá de 2,36 para 1,96 . Essa variação corresponde a um aumento de quase $5,5 \%$ na seletividade ao mono-etoxilado, para uma razão $\mathrm{OE} / \mathrm{ROH}_{0}$ estequiométrica, o que é um valor considerável em escala industrial.

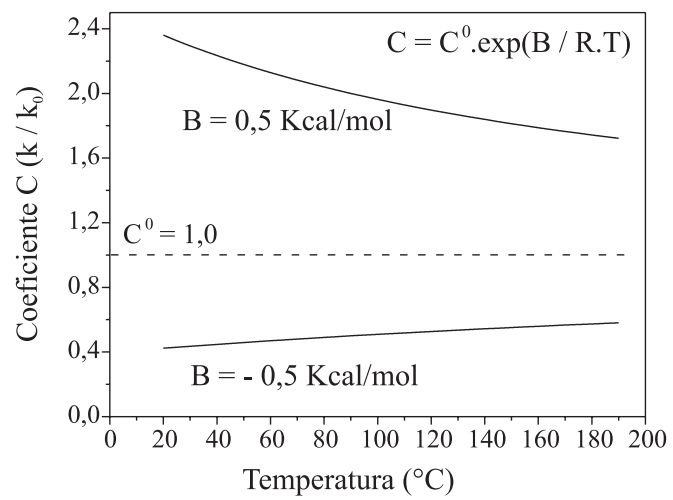

Figura 6. Variação do coeficiente $\mathrm{C}$ em função da temperatura, $\mathrm{B}=0,5 e$ $0,5 \mathrm{Kcal} / \mathrm{mol}$

Na Tabela 6 são mostrados os valores das constantes $C^{0}$ e $B$ (Kcal/mol) determinados a partir da etoxilação de alguns hidroxilados, na presença de $2 \%\left(\mathrm{~mol} / \mathrm{mol}_{\mathrm{ROH}}\right)$ de hidróxido de potássio $^{52,53}$. Na etoxilação dos álcoois 1-octanol e 1-dodecanol o valor do parâmetro $B$ é igual a zero, indicando que na etoxilação de álcoois primários, e.g. etanol, a temperatura de reação não exerce influência na seletividade. Neste caso, é importante que o reator tubular seja isolado termicamente, pois o aumento da temperatura favorece a velocidade da reação implicando, conseqüentemente, em um menor volume de reator.

Tabela 6. Parâmetros $C^{0}$ e $B$ para a etoxilação de alguns hidroxilados na presença de $\mathrm{KOH}^{52}$

\begin{tabular}{lcc}
\hline $\mathrm{ROH}_{0}$ & $C^{0}$ & $B(\mathrm{Kcal} / \mathrm{mol})$ \\
\hline 1 - Octanol & 2,0 & 0 \\
2 - Octanol & 0,08 & 3,8 \\
1 - Dodecanol & 4,1 & 0 \\
Nonilfenol & $7,4 *$ & $-1,2$ \\
\hline
\end{tabular}

$* \mathrm{~T}>130{ }^{\circ} \mathrm{C}$

Outro tópico que merece destaque na produção de etilenoglicóis e derivados é a formação de subprodutos. Dependendo do catalisador utilizado, ácido ou básico, haverá a formação predominante de determinado subproduto. Esta escolha é de fundamental importância para a determinação das condições de operação do processo e de separação.

\section{FORMAÇÃO DE SUBPRODUTOS}

\section{Catálise ácida}

Durante a reação de adição do óxido de eteno ao composto hidroxilado, $\mathrm{ROH}$, outros produtos também podem ser formados através de reações paralelas. A quantidade e o tipo desses subprodutos dependerá de uma grande variedade de fatores. Os catalisadores que conduzem à formação de água como subproduto, na etoxilação de álcoois, e conseqüentemente de etilenoglicóis (Reação $1, \mathrm{R}=\mathrm{H}$ ), não trazem melhorias tecnológicas para os atuais processos industriais os quais, em sua maioria, utilizam hidróxidos alcalinos como 
catalisadores, geralmente mais seletivos. Dentre os homólogos presentes na composição dos etilenoglicóis (EGs, Tabela $1, i \geq 2$ ) há uma quantidade significativa de MEG. A separação do MEG e do éter etílico do di-etilenoglicol (EEDEG) na coluna de destilação (Figura 1) não é total, devido ao fato de que eles apresentam pontos de ebulição muito próximos à pressão reduzida. À pressão atmosférica, p. ex., esses valores correspondem a 197 e $192{ }^{\circ} \mathrm{C}$, para o MEG e para o EEDEG, respectivamente ${ }^{54}$. Industrialmente, o EEDEG necessita ter pureza relativamente alta, uma vez que esse produto é matéria-prima na formulação de fluidos de freio, os quais, por motivo de segurança e legislação, apresentam especificações muito rígidas de viscosidade, densidade e estabilidade.

No sentido de melhorar a seletividade, Drew e Schaeffer estudaram a etoxilação de álcoois graxos, de $\mathrm{C}_{16} \mathrm{a} \mathrm{C}_{18}$, e analisaram o efeito de alguns catalisadores na formação paralela de etilenoglicóis (EGs) e de outros subprodutos, à temperatura de $125^{\circ} \mathrm{C}^{55}$. A presença de hidróxido de sódio como catalisador resultou na formação dos etoxilados esperados do reagente inicial e de $4 \%(\mathrm{~m} / \mathrm{m})$ de EGs, correspondendo exatamente à quantidade de água presente nos reagentes de partida (álcool e $\mathrm{NaOH}$ ). A presença de hidróxido de sódio não resultou na formação de outros produtos, além dos esperados pela Equação 1. No entanto, quando se empregou trifluoreto de boro $\left(\mathrm{BF}_{3}\right)$ como catalisador, a formação de EGs foi muito superior (19\%) e, além disso, houve a formação de produtos provenientes de outras reações, correspondentes a $13 \%$ em massa da mistura. A água presente nos reagentes de partida correspondeu à formação de aproximadamente $7 \%$ dos EGs. Portanto, a diferença de $12 \%$ foi originada pela formação de água em reações secundárias. A fração de $13 \%$, outros produtos, foi subdividida como contendo voláteis $(5 \%)$ e não voláteis $(8 \%)$. Os $5 \%$ voláteis continham 1,4-dioxana (aproximadamente 70\%) e 2-metil-dioxana (30\%). Os produtos classificados como não voláteis não foram identificados. No entanto, foi verificado que essa mistura não continha grupos $\mathrm{OH}$ e, portanto, não são enquadráveis entre os produtos da Tabela 1. O efeito do catalisador na produção de EGs, para quatro diferentes matérias-primas também foi estudado e, novamente, o catalisador $\mathrm{BF}_{3}$ foi o que mais contribui na formação de água e, conseqüentemente, de EGs ${ }^{56}$.

As Equações de 18 a 20 apresentam, de forma esquemática, as possíveis etapas para a formação de água e, conseqüentemente, de EGs nos produtos finais. Segundo essas reações, a formação desses hidroxilados pode ser proveniente da condensação aldólica do acetaldeído (Equações 19 e 20) ${ }^{20}$. Este, por sua vez, forma-se pelo rearranjo (abertura do anel) do óxido de eteno (Equação 18), o qual é facilitado na presença de um catalisador ácido ou de alta temperatura $^{4,57}$.<smiles></smiles><smiles>CC(=O)C=O</smiles><smiles>CC=CC(=O)C=O</smiles>

A catálise ácida com reações envolvendo o óxido de eteno pode complicar-se mais ainda pois esses sítios catalisam, mesmo a baixas temperaturas $\left(30-60{ }^{\circ} \mathrm{C}\right)$, a adição de moléculas de óxido de eteno em compostos contendo grupos carbonilas ${ }^{58}$ (p. ex., aldeídos), formando acetais.

Em determinadas condições reacionais, além do favorecimento da produção de EGs, ocorre a formação consecutiva de 1,4-dioxana, como discutido anteriormente. Alguns catalisadores sólidos ácidos também podem facilitar o surgimento da 1,4-dioxana através da ciclo-desidratação do $\mathrm{MEG}^{59}$, como descrito na Equação 21.

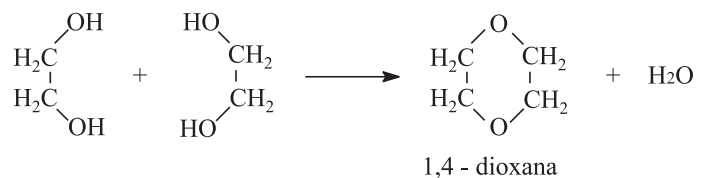

Na Tabela 7 são mostrados os catalisadores que foram avaliados nessa reação, todos eles apresentando sítios ácidos de Lewis ou de Brönsted. Pode-se observar que a argila montmorilonita e a zeólita HZSM-5 (tendo Si/Al = 40), ambas com certa quantidade de sítios de Brönsted, foram os materiais que apresentaram a maior seletividade na obtenção de 1,4-dioxana. Quando se utilizou a zeólita HZSM-5 contendo sítios ácidos fracos $(\mathrm{Si} / \mathrm{Al}=280)$ não se observou conversão significativa de MEG, indicando que a presença de sítios ácidos fortes são de fundamental importância para que essa reação ocorra. Dependendo das condições reacionais e da força ácida desses sítios, pode ocorrer ainda a abertura dos anéis dos éteres cíclicos, ocorrendo a formação de aldeídos e olefinas ${ }^{60}$.

Tabela 7. Ciclo-desidratação do MEG catalisada por catalisadores ácidos sólidos ${ }^{59}$

\begin{tabular}{lccc}
\hline Catalisador & $\begin{array}{c}\text { Tempo } \\
\text { (h) }\end{array}$ & $\begin{array}{c}\text { Conversão } \\
\text { de MEG (\%) }\end{array}$ & $\begin{array}{c}\text { Seletividade à } \\
\text { 1,4-dioxana (\%) }\end{array}$ \\
\hline $\mathrm{B}_{2} \mathrm{O}_{3}-\mathrm{Al}_{2} \mathrm{O}_{3}$ & 3,0 & $\ldots$ & $\ldots$ \\
$\mathrm{AlPO}_{4}$ & 3,0 & $\ldots$ & $\ldots$ \\
$\mathrm{Cu}-\mathrm{NaY}^{\text {a }}$ & 2,0 & 8,1 & 27,0 \\
$\mathrm{HY}^{\text {a }}$ & 3,0 & 16,3 & 13,0 \\
$\mathrm{ZrOCl}_{2} \cdot 8 \mathrm{H}_{2} 0$ & 2,5 & 22,0 & 19,7 \\
Montmorilonita $^{\text {b }}$ & 2,5 & 46,5 & 38,6 \\
HZSM-5 $^{\text {a }}$ & 1,5 & 100 & 73,0 \\
\hline
\end{tabular}

${ }^{\mathrm{a}}$ Zeólitas (Peneiras Moleculares); ${ }^{\mathrm{b}}$ Argila Pilarizada

\section{Catálise básica}

Uma das possibilidades de se realizar a etoxilação em meio básico é usando aminas terciárias $\mathrm{R}_{3} \mathrm{~N}$ (i. e. $\mathrm{R}=\mathrm{CH}_{3} \mathrm{CH}_{2}-$ ou $\mathrm{CH}_{3} \mathrm{CH}_{3} \mathrm{CH}_{2}-$ ), as quais, ao contrário das primárias e secundárias, não possuem hidrogênio ativo, tal como explicado na introdução deste trabalho. Quando se utilizam aquelas aminas como catalisador na etoxilação de álcoois de baixa massa molecular observa-se que, mesmo não possuindo o "hidrogênio ativo", a concentração de $\mathrm{R}_{3} \mathrm{~N}$ no meio diminui ao longo do tempo. A concentração de tripropilamina pode cair de $1,3 \%(\mathrm{~m} / \mathrm{m})$ na mistura reacional inicial para $0,3 \%$ após um período de 2 h e 30 min de reação ${ }^{61}$, mesmo quando a massa total da mistura permanece aproximadamente constante. Se esse tempo for estendido para $8 \mathrm{~h}$, a concentração de tripropilamina cai ainda mais significativamente para $0,001 \%$. Por outro lado, uma mistura reacional, após a destilação para a remoção do catalisador trietilamina (p. e. $=89^{\circ} \mathrm{C}$ ), ainda apresenta atividade catalítica ${ }^{62}$. Estudos realizados por Poskrobko e colaboradores mostram que a trietilamina reage com o óxido de eteno formando o intermediário iônico $\mathrm{R}_{3} \mathrm{~N}^{+} \mathrm{CH}_{2} \mathrm{CH}_{2} \mathrm{O}^{-}$. Este composto apresenta atividade catalítica, pois gera o ânion alcóxido $\mathrm{RO}^{-}$que, por 
sua vez, possui um caráter nucleofílico mais acentuado que o ROH, e, portanto, é mais reativo frente ao óxido de eteno (Equação 22). Ao longo do tempo, um dos grupos $\mathrm{R}$ deste intermediário é liberado, através da eliminação de Hofmann, formando uma alquiletanoldiamina e uma olefina. Se a amina originalmente utilizada como catalisador for a trietilamina, a olefina formada será o eteno $\left(\mathrm{H}_{2} \mathrm{C}=\mathrm{CH}_{2}\right)$. $\mathrm{O}$ composto alquil-etanolamina, por possuir um grupo hidroxila, apresenta reatividade elevada com o óxido de eteno, ocorrendo a formação de uma mistura de alquil-etanolaminas $(\mathrm{R})_{2} \mathrm{~N}\left(\mathrm{CH}_{2} \mathrm{CH}_{2} \mathrm{O}\right)_{i} \mathrm{H}$ de alto peso molecular $(i>1)$ e, conseqüentemente, não-volátil ${ }^{61,62}$. Nos experimentos, a formação desses subprodutos causou uma coloração marrom, provavelmente devido à presença de compostos de alto peso molecular ${ }^{61}$, o que comercialmente significa uma queda na qualidade dos produtos etoxilados, que são incolores.

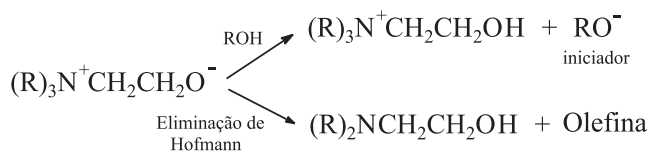

As conclusões que podem ser obtidas dos resultados apresentados, usando catalisadores ácidos ou básicos, são que é possível desfavorecer a formação de subprodutos através de uma seleção criteriosa do catalisador, da ausência de água no reagente de partida $\mathrm{ROH}$, do emprego de uma menor temperatura de reação e da escolha do próprio reagente $\mathrm{ROH}$. Na verdade, espera-se que um processo industrial que empregue um catalisador, ácido ou básico, para etoxilação de reagentes do tipo $\mathrm{ROH}$, opere em condições de temperatura mais baixa, em comparação àquele não catalítico.

\section{NOVA TECNOLOGIA - CARBONATO DE ETILENO}

Até o momento, poucos processos utilizando o dióxido de carbono tornaram-se economicamente viáveis, apesar da possibilidade de utilização desse reagente na obtenção de produtos orgâni$\cos ^{62}$. Normalmente, a ativação do dióxido de carbono catalisada por metais suportados, ou óxidos metálicos para a síntese de orgânicos, resulta em rendimentos muito inferiores quando comparados aos tradicionais métodos de preparação. Entretanto, um dos processos industriais mais promissores para o carbono é seu uso na síntese de policarbonatos e de carbonatos cíclicos ${ }^{63}$. Deveras, uma grande variedade de catalisadores desde bi-funcionais, homogêneos ancorados em polímeros, complexos de antimônio, óxidos mistos de $\mathrm{Mg}$-Al e até zeólitas básicas vêm sendo estudados para esse processo $^{64-68}$.

O interesse em explorar o uso do dióxido de carbono, especificamente para a produção de carbonato de etileno, vem crescendo nos últimos anos e, atualmente, já existe uma planta piloto em operação, de propriedade da Mitsubishi Chemical, para a conversão de óxido de eteno a mono-etileno glicol (MEG) via carbonato de etileno ${ }^{5}$ (Equação 23). A nova tecnologia, que utiliza um catalisador à base de sais de fosfônio (por exemplo, $\mathrm{Ph}_{3} \mathrm{PCH}_{3} \mathrm{I}$ ), apresenta uma seletividade ao MEG de 99\%, utilizando uma razão molar global de água/óxido de eteno menor que dois ${ }^{69}$. O processo convencional de produção do MEG utiliza um grande excesso de água (razão molar $\mathrm{OE} / \mathrm{H}_{2} \mathrm{O} \mathrm{em}$ torno de 25) e a seletividade é de apenas $90 \%$. Uma das grandes dificuldades no desenvolvimento dessa nova tecnologia é a separação do catalisador do meio reacional, de forma que ele possa ser realimentado ao reator. Outro fator que tem favorecido o desenvolvimento dessa tecnologia é o fato de que as plantas de óxido de eteno produzem uma quantidade apreciável de dióxido de carbono como subproduto; é um destino nobre para um composto que vem sendo constantemente lançado à atmosfera.

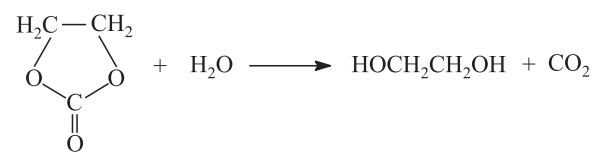

Uma vez que têm surgido novos catalisadores sólidos para essa reação, o potencial e a expectativa de resolver o problema de separação do catalisador utilizado na obtenção de carbonato de etileno vêm crescendo. Um dos materiais mais promissores tem sido o uso de zeólitas trocadas com césio ou impregnadas com acetato de césio ${ }^{68}$. Por ter um grande raio iônico, este cátion garante uma maior basicidade do ânion, necessária à catálise, em comparação com cátions de menor raio iônico (i. e. sódio e potássio) ${ }^{70}$. Na Figura 7 é mostrado um possível mecanismo de reação para a obtenção de carbonato de etileno a partir de dióxido de carbono e OE, sobre a superfície de um óxido metálico ${ }^{68}$. Nesse mecanismo, o dióxido de carbono é adsorvido sobre os sítios básicos de Lewis (i. e., $\mathrm{O}^{2-}$ ) formando uma superfície carbonatada. A força e o número de sítios básicos são fatores muito importantes na ativação do dióxido de carbono ${ }^{71,72}$. O óxido de eteno, por sua vez, através do átomo de oxigênio é adsorvido em um sítio ácido de Lewis, vizinho ao anterior ( $\mathrm{M}^{2+}$ na Figura 7). O dióxido de carbono então reage com um dos átomos de carbono do OE adsorvido gerando um oxi-ânion o qual, subseqüentemente, dessorve resultando no produto carbonatado cíclico.

No mecanismo da Figura 7 a basicidade e, conseqüentemente, a capacidade de adsorção de dióxido de carbono é favorecida sobre óxidos metálicos, puros ou mistos. No entanto, a atividade é mais pronunciada em materiais com sítios básicos que possuam alta área superficial específica, como acontece com as zeólitas, indicando que a porosidade desses materiais é essencial para um bom desempenho catalítico.

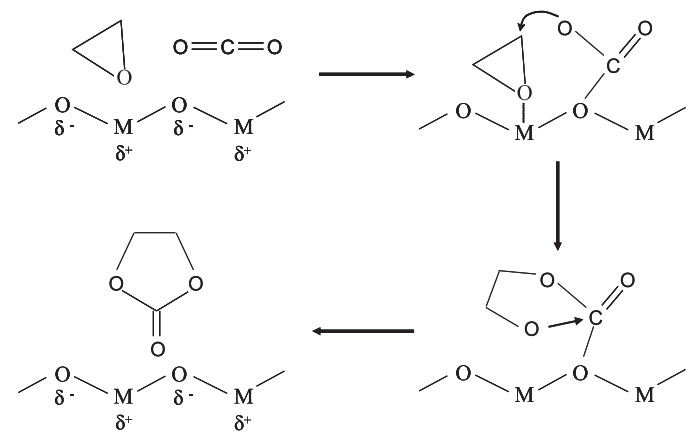

Figura 7. Provável mecanismo de ciclo adição do dióxido de carbono ao óxido de eteno sobre a superfície de um óxido metálico. Reproduzido da ref. 68, com permissão da Elsevier Science

Os interesses industriais na nova tecnologia para a obtenção de carbonato de etileno estendem-se além dos menores custos de processo e das melhorias obtidas com a alta seletividade ao MEG. O transporte do óxido de eteno a longas distâncias tem um custo elevado e várias dificuldades operacionais, visto que essa substância química é muito perigosa e instável ${ }^{73}$. Por outro lado, o carbonato de etileno, que é uma sustância muito estável em condições ambientes, pode ser convertido novamente a óxido de eteno com alta seletividade e a um custo modesto ${ }^{69,74}$. Além da vantagem do transporte facilitado, há a possibilidade do emprego do carbonato de etileno na substituição do óxido de eteno na produção de seus derivados e no uso como solvente especial, pois o mesmo é líquido acima de $39^{\circ} \mathrm{C}$. 


\section{CONSIDERAÇÕES FINAIS}

Os produtos resultantes da etoxilação de compostos hidroxilados apresentam elevada importância comercial, tendo em vista suas possíveis aplicações. Este trabalho apresentou vários aspectos relacionados a reações catalíticas do óxido de eteno com hidroxilados $\mathrm{ROH}$, indicando as direções das pesquisas nessa área e com possíveis aplicações industriais. As principais características buscadas num processo industrial foram relacionadas com os mecanismos de reação e formação de subprodutos. Foi apresentada, também, uma ferramenta matemática simplificada, utilizada freqüentemente na determinação das variáveis de processo e na escolha do catalisador.

O desenvolvimento de um novo processo de etoxilação, baseado na produção exclusiva de carbonato de etileno, tem atraído a atenção de pesquisadores e de empresas, uma vez que esse composto pode apresentar diversas aplicações como intermediário químico e como produto final. Espera-se, portanto, que no futuro, seguindo essa tendência de melhorias dos atuais processos e desenvolvimento de novas tecnologias, a produção de óxido de eteno seja impulsionada num ritmo ainda maior, garantindo a vitalidade desse mercado.

\section{AGRADECIMENTOS}

A Oxiteno pelo incentivo no desenvolvimento deste trabalho e ao CNPq pela concessão de bolsa DTI a L. Martins. Agradecemos, também, ao Prof. M. Yonashiro do DQ/UFSCar, pelas discussões acerca dos mecanismos de reação.

\section{REFERÊNCIAS}

1. Guia da Indústria Química Brasileira, ABIQUIM, 2003.

2. http://www.oxiteno.com.br, acessada em Julho 2004.

3. "CW Product Focus" (Coluna informativa); Chemical Week 1995, 2, 44

4. Parker, R. E.; Isaacs, N. S.; Chem. Rev. 1959, 59, 737.

5. Moore, S.; Chemical Week 2002, 6, 25.

6. Rebsdat, S.; Mayer, D. Em Ulmann's Encyclopedia of Industrial Chemistry; Elvers, B.; Rounsaville, J. F.; Schulz, G., eds.; 5 th ed., VCH: Germany, 1985, vol. A10.

7. Miller, J. H.; Corrigan, T. E.; Hydrocarbon Processing 1967, 46, 176

8. Matignon, C.; Moureu, H.; Dode, M.; Bull. Soc. Chim. Fr. 1934, 5, 1308.

9. Hreczuch, W.; Poskrobko, H.; Pyzalski, K.; Ind. Eng. Chem. Res. 1999, 28,2225 .

10. Bares, M.; Burczyk, B.; Piasecki, A.; Sokolowski, A.; Tenside, Surfactants, Deterg. 1992, 29, 138.

11. Ingold, C. K.; Structure and Mechanism in Organic Chemistry, Cornell University Press: New York, 1953, cap. 3.

12. Schonfeldt, N.; Surface Active Ethylene Oxide Adducts, Pergamon Press, 1969, cap. 2.

13. Lamaty, G.; Maleq, R.; Selve, C.; Sivade, A.; Wylde, J.; J. Chem. Soc., Perkin Trans. 2 1975, 10, 1119.

14. Santacesaria, E.; Iengo, P.; Di Serio, M. Em Design and Selection of Performance Surfactants; Karsa, D. R., ed.; Sheffield: Manchester, 1999, cap. 5.

15. Klug, O.; Parlagh, G.; Rusznak, I.; Sallay, P.; Farkas, L.; ACH - Models in Chemistry 1997, 134, 265.

16. Reinhardt, C.; Solvent Effects in Organic Chemistry, Weinheim: New York, 1979.

17. Kosswig, K. Em ref. 6, vol. A25.

18. Flory, P. J.; Principles of Polymer Chemistry, $9^{\text {th }}$ ed., Cornell University Press: London, 1975

19. Gee, G.; Higginson, W. C. E.; Levesley, P.; Taylor, K. J.; J. Chem. Soc. 1959, 2, 1338.

20. Orvik, J.A.; J. Am. Chem. Soc. 1976, 98, 3322.

21. Streitwieser, A.; Heathcock, C. K.; Kosower, E. M.; Introduction to Organic Chemistry, $4^{\text {th }}$ ed., Macmillan: New York, 1992.

22. Sallay, P.; Morgos, J.; Farkas, L.; Bartha, B.; Rusznak, I.; Periodica Polytechnica - Chemical Engineering 1979, 23, 29.

23. Malherbe, F.; Besse, J.-P.; Wade, S. R.; Smith, W. J.; Catal. Lett. 2000, $67,197$.
24. Hama, I.; Sasamoto, H.; Okamoto, T.; J. Am. Oil Chem. Soc. 1997, 74, 817.

25. Climent, M. J.; Corma, A.; Iborra, S.; Velty, A.; J. Mol. Catal. A: Chem. 2002, 182-183, 327

26. Malherbe, F.; Depège, C.; Forano, C.; Besse, J. P.; Atkins, M. P.; Sharma, B.; Wade, S. R.; Appl. Clay Sci. 1998, 13, 451

27. Kim, D.; Huang, C.; Lee, H.; Han, I.; Kang, S.; Kwon, S.; Lee, J.; Han, Y.; Kim, H.; Appl. Catal., A 2003, 249, 229.

28. Atkins, M. P.; Eur. pat. 250,168 1987.

29. Schroeder, W.; Ger. pat. DE 4,323,474 1995

30. Chen, N. Y.; Garwood, W. E.; Dwyer, F. G.; Shape Selective Catalysis in Industrial Applications, Marcel Dekker: New York, 1989, cap. 3.

31. Nagy, J. B.; Bodart, P.; Hannus, I.; Kiricsi, I.; Synthesis, Characterization and Use of Zeolitic Microporous Materials, $1^{\text {st }}$ ed., DecaGen: Hungary, 1998.

32. Csicsery, S. M.; Zeolites 1984, 4, 202.

33. Weitkamp, J.; Solid State Ionics 2000, 131, 175.

34. Cuscurida, M.; Knifton, J. F.; Dai, P.-S. E.; US pat. 5,256,828 1993.

35. Weibull, B.; Nycander, B.; Acta Chemica Scandinavica 1954, 8, 847.

36. Weibull, B; Acta Chemica Scandinavica 1995, 49, 207.

37. Hreczuch, W.; Szymanowski, J.; J. Am. Oil Chem. Soc. 1996, 73, 73.

38. Farkas, L.; Morgos, J.; Sallay, P.; Rusznak, I.; Bartha, B.; Verges, G.; J. Am. Oil Chem. Soc. 1981, 58, 650.

39. Sallay, P.; Morgos, J.; Farkas, L.; Rusznack, I.; Verges, G.; Bartha, B.; Tenside, Surfactants, Deterg. 1980, 17, 298.

40. Tesser, R.; Di Serio, M.; Santacesaria, E.; Catal. Today 2003, 79-80, 323.

41. Santacesaria, E.; Di Serio, M.; Tesser, R.; Catal. Today 1995, 24, 23.

42. Santacesaria, E.; Di Serio, M.; Garaffa, R.; Addino, G.; Ind. Eng. Chem. Res. 1992, 31, 2419.

43. Di Serio, M.; Tesser, R.; Felippone, F.; Santacesaria, E.; Ind. Eng. Chem. Res. 1995, 34, 4092.

44. Braun, R.; Schönbucher, A.; Chem. Eng. Technol. 2001, 10, 991.

45. Miller, S. A.; Ethylene and its Industrial Derivatives, Ernest Benn Limited: London, 1969, cap. 7.

46. Flory, P. J.; J. Am. Chem. Soc. 1940, 62, 1561.

47. Di Serio, M.; Tesser, R.; Dimiccoli, A.; Santacesaria, E; Ind. Eng. Chem. Res. 2002, 41, 5196

48. Gold, L.; J. Chem. Phys. 1958, 28, 91.

49. Natta, G.; Mantica, E.; J. Am. Chem. Soc. 1952, 74, 3152

50. Ishii, Y.; Sekiguchi, S.; Hayakawa, A.; Kogyo Kagaku Zasshi 1962, 65, 1041.

51. Sallay, P.; Farkas, L.; Rusznak, I.; J. Am. Oil Chem. Soc. 1990, 67, 209.

52. Santacesaria, E.; Di Serio, M.; Iengo, P.; Stud. Surf. Sci. Catal. 1999, 122, 267.

53. Charpentier, J. C.; Advances in Chemical Engineering, Academic Press: New York, 1981, vol. 11.

54. Reid, R. C.; Prausnitz, J. M.; Sherwood, T. K.; The Properties of Gases and Liquids, $3^{\text {rd }}$ ed., McGraw-Hill, 1977.

55. Drew, H. F.; Schaeffer, J. R.; Ind. Eng. Chem. 1958, 50, 1253.

56. Nagase, K.; Sakaguchi, K.; Kogyo Kagaku Zasshi 1961, 64, 1199.

57. Dartt, C. B.; Davis, M. E.; Catal. Today. 1994, 19, 151.

58. Meskens, F. A. J.; Synthesis 1981, 7, 501.

59. Wali, A.; Pillai, S. M.; Unnikrishnan, S.; Satish, S.; J. Mol. Catal. A: Chem. 1996, 109, 149.

60. Neri, C.; Buonomo, F.; Eur. pat. 100,117 1983

61. Poskrobko, J.; Milchert, E.; Poskrobko, H.; Dziwiski, E.; J. Chem. Technol. Biotechnol. 1996, 67, 84

62. Poskrobko, H.; Poskrobko, J.; Hreczuch, W.; Sobczynska, A.; Szymanowski, J.; J. Chem. Technol. Biotechnol. 2000, 75, 547.

63. Darensourg, D. J.; Holtcamp, M. W.; Coord. Chem. Rev. 1996, 153, 155.

64. Lu, X.-B.; He, R.; Bai, C.-X.; J. Mol. Catal. A: Chem. 2002, 186, 1.

65. Kim, H. S.; Kim, J. J.; Kwon, H. N.; Chung, M. J.; Lee, B. G.; Jang, H. G.; J. Catal. 2002, 205, 226.

66. Nomura, R.; Ninagawa; Matsuda, H.; J. Org. Chem. 1980, 45, 3735.

67. Yamaguchi, K.; Ebitani, K.; Yoshida, T.; Yoshida, H.; Kaneda, K.; J. Am. Chem. Soc. 1999, 121, 4526.

68. Tu, M.; Davis, R. J.; J. Catal. 2001, 199, 85.

69. Ozero, B. J.; Procelli, J. V.; Hydrocarbon Processing 1984, 63, 55.

70. Davis, R. J.; Doskocil, E. J.; Bordawekar, S.; Catal. Today 2000, 62, 241.

71. Davis, R. J.; J. Catal. 2003, 216, 396.

72. Monteiro, J. F.; Veloso, C. O.; Actas del XIII Congresso Argentino de Catálise y del $2^{\circ}$ Congresso de Catálise do Mercosul, Córdoba, Argentina, 2003.

73. http://www.ethyleneoxide.com, acessada em Julho 2004.

74. Weast, R.C.; Handbook of Chemistry and Physics, 64 ${ }^{\text {th }}$ ed., CRC Press, 1984. 